\title{
Psicologia e Profissão: Neurose Profissional e a Atuação do Psicólogo Organizacional Frente à Questão
}

Psychology and Profession: Professional Neurosis and the Performance of the Organizational Psychologist in Relation to the Matter

Psicología y Profesión: Neurosis Profesional y la Actuación del Psicólogo Organizacional Frente a la Cuestión

Ludmilla Cristine Santos, Edward Goulart Júnior, Luiz Carlos Canêo, Maria Cristina Frollini Lunardelli

Pérola Lozano Teixeira de Carvalho

Universidade Estadual Paulista Júlio de Mesquita Filho

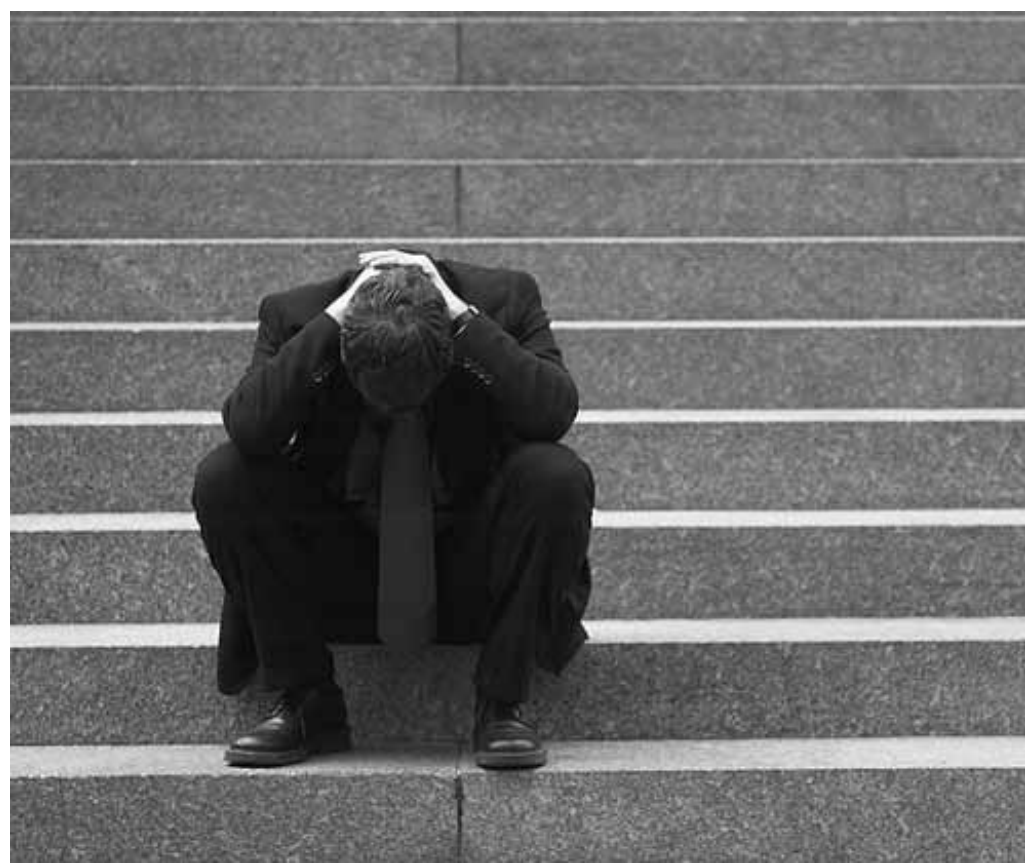


Resumo: Este artigo pretende fazer um levantamento bibliográfico sobre a neurose profissional, cujos sintomas são entendidos como a expressão simbólica de um conflito psíquico que se desenvolve a partir de uma situação organizacional ou profissional determinada. O diagnóstico é formado a partir das queixas mencionadas, da história de trabalho e da análise da situação de trabalho atual. Entende-se que condições estressantes de trabalho, associadas ao contexto social de desemprego e competitividade, contribuem para o aparecimento de doenças mentais como a neurose profissional. As formas de tratamento para essa doença, além da psicoterapia individual, envolvem a ação integrada de uma equipe multiprofissional capacitada para lidar com o sofrimento psíquico do trabalhador e com os aspectos sociais e de intervenção nos ambientes de trabalho. Ressalta-se a carência de literatura sobre o tema estudado e a importância de se ampliar a discussão sobre os fatores de risco no trabalho, os determinantes psíquicos para o desenvolvimento da neurose profissional e o papel do psicólogo no contexto de prevenção e promoção da saúde mental.

Palavras-chave: Neurose. Qualidade de vida no trabalho. Psicologia organizacional. Saúde mental.

\begin{abstract}
This article has the intent to do a bibliographical research about professional neurosis whose symptoms are understood as a symbolical expression of a psychological conflict whose development is found connected to a organizational situation or professionally determined. The diagnosis of professional neurosis is formed through the mentioned complaints, the work history and the analysis of the worker's current job. It is understood that stressful working conditions, associated with the social context of unemployment and competitiveness, contribute to mental diseases, among those the professional neurosis. Methods of treatment for professional neurosis, besides individual psychotherapy, include the integrated action of a multi-professional team, capable of leading and give support to the psychological suffering of the worker and to the social aspects of intervention in the work environment. It stands out in the research the lack of literature about the subject and also the importance of extending the discussion about those risk factors at work, the psychological determinants for the development of professional neurosis and the role of the psychologist in the context of prevention and promotion of mental health.
\end{abstract}

Keywords: Neurosis. Quality of work life. Industrial psychology. Mental health.

Resumen: Este artículo pretende hacer un levantamiento bibliográfico sobre la neurosis profesional, cuyos síntomas son entendidos como la expresión simbólica de un conflicto psíquico que se desarrolla a partir de una situación organizacional o profesional determinada. El diagnóstico es formado a partir de las quejas mencionadas, de la historia de trabajo y del análisis de la situación de trabajo actual. Se entiende que condiciones estresantes de trabajo, asociadas al contexto social de desempleo y competitividad, contribuyen para la aparición de dolencias mentales como la neurosis profesional. Las formas de tratamiento para esa dolencia, además de la psicoterapia individual, envuelven la acción integrada de un equipo multiprofesional capacitado para tratar con el sufrimiento psíquico del trabajador y con los aspectos sociales y de intervención en los ambientes de trabajo. Se destaca la carencia de literatura sobre el tema estudiado y la importancia de ser ampliada la discusión sobre los factores de riesgo en el trabajo, los determinantes psíquicos para el desarrollo de la neurosis profesional y el papel del psicólogo en el contexto de prevención y promoción de la salud mental.

Palabras clave: Neurosis. Calidad de vida en el trabajo. Psicologia industrial. Salud mental.

\section{A Organização Mundial da Saúde estima que} cerca de $30 \%$ da população trabalhadora do mundo sofra de transtornos mentais menores (como depressão, ansiedade, distúrbios somatoformes e neurastenia) e de 5 a $10 \%$, de transtornos mentais graves (como transtorno de humor, transtorno psicótico e depressão grave). Esses distúrbios, além de gerarem despesas para a sociedade - mediante custeio de tratamentos de saúde e concessão de benefícios previdenciários -, causam sofrimento psíquico tanto para as pessoas portadoras como para seus familiares e amigos, entre outros. Uma estimativa recente avaliou os custos para o Brasil decorrentes de acidentes e doenças ocupacionais - R\$ 12,5 bilhões anuais para as empresas e $\mathrm{R} \$ 20$ bilhões anuais para os contribuintes (Brasil, 2001).

Conforme destacam Camargo e Neves (2004), hoje se sabe que a maior parte das doenças é ocasionada por uma combinação de fatores biológicos, psicológicos e sociais. Embora não se estabeleça uma relação clara entre o estado afetivo e a condição física 
do indivíduo, é cada vez mais evidente que o comprometimento da saúde mental vai desempenhar significativo papel no enfraquecimento do sistema imunológico, no desenvolvimento de certas doenças físicas e na morte prematura.

Os autores ressaltam ainda que, ao tratar das questões ligadas à saúde mental e trabalho, há uma grande complexidade para se estabelecer o nexo causal das doenças relacionadas com o trabalho, principalmente quando se envolvem benefícios previdenciários. Destacam que a classificação das doenças mentais é dividida em três grupos: 1) grupo I: doenças profissionais - nas quais o trabalho representa um nexo causal evidente, como nas neurointoxicações ocupacionais provocadas por mercúrio, por exemplo; 2) grupo II: o trabalho pode ser um fator de risco para patologias, mas não necessariamente. Estão nesse grupo o alcoolismo crônico, transtornos do ciclo sono-vigília, etc; 3 ) grupo III: nesse caso, o trabalho é desencadeador de um distúrbio latente (concausalidade), como os episódios depressivos, a neurose profissional e a neurastenia, entre outros a neurose profissional, o foco deste texto, pertence ao grupo III.

De acordo com a Portaria MS (Ministério da Saúde) n.1.339/1999, a neurose profissional/ ocupacional faz parte da lista de transtornos mentais e do comportamento relacionados ao trabalho, e, segundo a Classificação Internacional de Doenças (CID-10), está incluída em "outros transtornos neuróticos especificados".

Este artigo tem como intenção fazer um levantamento bibliográfico do conceito de neurose profissional/ocupacional, tendo em vista os fatores de risco no trabalho que poderiam contribuir para o desenvolvimento desse distúrbio, e abordar as possíveis intervenções do psicólogo organizacional no contexto de trabalho.

Entende-se que o psicólogo que atua nas organizações deve ter sólidos conhecimentos sobre esse transtorno mental, e, ao utilizar uma abordagem sistêmica, também compreender o indivíduo em sua totalidade, avaliando suas condições de trabalho e de vida. Para tanto, a contextualização do tema saúde mental e trabalho torna-se relevante, assim como uma explanação do conceito de neurose.

\section{Contextualizando saúde mental e suas relações com o trabalho}

O critério de normalidade/anormalidade no que se refere à saúde e doença mental, de acordo com Albuquerque (1978), alterou-se com a própria modificação da ordem social. Assim, com a Revolução Francesa e, em consequência, com a ascensão da burguesia ao poder, o critério de normal/patológico passa a ser o trabalho. Segundo Resende (1987), esse critério também foi utilizado no Brasil e, apesar de algumas particularidades, todos aqueles que se demonstrassem improdutivos eram excluídos da sociedade. Para ser considerado normal, era necessário estar em atividade e enquadrar-se nos moldes de trabalho estabelecidos pelos donos dos meios de produção - detentores do poder, do dinheiro e, principalmente, dos empregos.

Resende ressalta que, até meados da década de 70, a atenção quanto à saúde do trabalhador recaía apenas na questão financeira, mas havia uma preocupação com o trabalhador para que este pudesse continuar a desempenhar corretamente sua função e a trabalhar em favor da lucratividade. 
Mendes e Cruz (2004) afirmam que o trabalho traz consequências paradoxais para a integridade física e psíquica dos indivíduos.
De acordo com Codo, Soratto e VasquesMenezes (2004), somente após a década de 80 é que começaram as publicações e as discussões sobre a relação existente entre saúde mental e trabalho; após essa década, foi levantada a importância de ações preventivas nesse contexto.

As mudanças tecnológicas e organizacionais do trabalho aceleraram a preocupação quanto ao comportamento no plano social e individual do trabalhador e quanto às consequências dessas transformações em sua saúde. Cada vez mais é reconhecida a relação de influência da atividade ocupacional sobre o bem-estar emocional do empregado (Guimarães, Cardoso, Grubits, \& Martins, 1999).

O trabalho é a fonte de subsistência para o ser humano. É por meio dele que o homem cria e constrói os bens necessários à própria sobrevivência, assim como obtém recursos para a aquisição de outros bens - estes produzidos por outras pessoas. Contudo, o trabalho também pode ser fonte de sofrimento, alienação e degradação humana (Brasil, 2001; Correia, 2000).

De acordo com Codo et al. (2004), o trabalho pode ser vivenciado como possibilidade de crescimento, de socialização e de humanização do indivíduo; no entanto, pode também ser causador de doenças, devido à estrutura social vigente e às diferentes maneiras de se organizar o trabalho.

Em relação ao adoecimento, fatores como a atual conjuntura política e econômica, a precarização do trabalho e a reestruturação produtiva em curso acelerado têm acentuado essa condição. Ressalta-se que essa precarização engloba alguns aspectos como a desregulamentação e a perda de direitos trabalhistas e sociais, a legalização dos trabalhos temporários e a informalidade do trabalho. As consequências desses sinais são o aumento do número de trabalhadores autônomos e subempregados, a fragilização das organizações sindicais e a terceirização, acompanhada de práticas de intensificação de trabalho e/ou aumento da jornada, o acúmulo de funções, maior exposição aos fatores de risco para a saúde, o descumprimento de regulamentos de proteção à saúde e segurança e o rebaixamento dos níveis salariais e o aumento da instabilidade no emprego (Brasil, 2001).

Mendes e Cruz (2004) afirmam que o trabalho traz consequências paradoxais para a integridade física e psíquica dos indivíduos. De um lado - como atividade produtiva ontológica e constituinte da identidade do trabalhador -, assume papel essencial para assegurar a saúde; de outro, quando adquire o sentido de algo penoso - que causa malestar, é exercido em condições precárias e não oferece oportunidades de desenvolvimento profissional -, pode contribuir para o adoecimento dos trabalhadores, decorrente tanto da compulsão pelo trabalho (workaholic) como pelo não trabalho (desemprego).

Nascimento e Bulgacov (1999) argumentam que os problemas causados pelas doenças ocupacionais deveriam receber mais atenção por parte das organizações e de seus dirigentes, pois o ônus delas decorrente é significativo e envolve custos em relação à assistência médica, à redução de produtividade, à falta de trabalho, aos programas de prevenção e ao absenteísmo.

Glina, Rocha, Batista e Mendonça (2001) apresentaram sete casos de doença mental, atendidos nos Centros de Referência em Saúde do Trabalhador (CEREST) de Santo 
Amaro e André Gobois, no período de 1994 a 1997. Os métodos utilizados foram a análise das anamneses e os prontuários, buscando estabelecer o nexo causal do adoecimento e a situação de trabalho. As situações relatadas nesse estudo caracterizaram-se por: condições de trabalho nocivas (ruído, calor, vibração e produtos químicos), problemas relacionados à organização do trabalho (jornadas extensas, sobrecarga de tarefas, pressão por produção, metas irreais) e gestão inadequada (remanejamento para uma função inadequada às características da personalidade, transferência para uma região muito distante da moradia, assalto, violência e acidente de trabalho).

Nesse estudo, os autores indicam que os diagnósticos dos casos analisados foram variáveis: síndromes pós-traumáticas ligadas a assaltos, casos psicóticos orgânicos ligados a acidentes ou exposição a produtos químicos, síndromes neuróticas de fadiga, depressivas, paranoides, de adaptação e de reação ao estresse grave. Pôde-se concluir, a partir da pesquisa realizada, que todos os casos se relacionam com as situações de trabalho.

Nascimento e Bulgacov (1999) realizaram estudo com o objetivo de compreender as mudanças organizacionais e a sua relação com o estresse ocupacional. Os dados foram coletados em questionários aplicados a 35 gerentes de níveis intermediário e técnico oriundos de diferentes organizações situadas em Curitiba e em Municípios vizinhos. Um dos resultados obtidos envolve a vinculação entre alto e moderado grau de stress dos indivíduos com maior número de fontes estressoras no trabalho, ocasionado, provavelmente, pela gestão inadequada dos processos de mudança organizacional.

Cooper e Kelly (1993) definem stress ocupacional como um problema de natureza perceptiva, resultante da incapacidade do indivíduo de lidar com as pressões resultantes do trabalho e que causa impacto na sua saúde física e mental e na satisfação com o trabalho. Tal situação de tensão exagerada afeta não somente os trabalhadores como também as organizações. Constata-se que cada vez mais estudos demonstram o quanto o adoecimento mental se relaciona com as condições de trabalho, produzindo consequências desastrosas tanto para as pessoas como para as organizações, principalmente na redução acentuada da produtividade e na intensificação dos conflitos interpessoais no trabalho.

Entre os modelos de explicação das relações entre saúde mental e trabalho, destacamse principalmente duas correntes: a) a psicopatologia do trabalho - denominada psicodinâmica do trabalho a partir dos estudos de Dejours, a qual enfatiza a psicodinâmica do trabalho na vida dos trabalhadores ao analisar os aspectos dessa atividade que podem favorecer a saúde ou a doença; b) a interrelação entre stress e trabalho, que apresenta grande complexidade, decorrente inclusive das inúmeras variações no conceito de stress.

Destaca-se a definição de Frankenhaeuser e Garell (1976), Kalimo (1980) e Levi (1988), (como citados por Glina et al, 2001, p. 608), de stress ocupacional como "um desequilíbrio entre as demandas do trabalho e a capacidade de resposta dos trabalhadores". Nessa segunda corrente, há maior preocupação com a determinação dos fatores potencialmente estressantes em uma situação de trabalho. Por fatores potencialmente estressantes no trabalho, são entendidas aquelas situações capazes de causar a quebra do equilíbrio interno do indivíduo, que provocam um conjunto de 
De acordo com Tamayo, Lima e Silva (2004), o stress ocupacional é resultante das exigências do trabalho e das habilidades do trabalhador para enfrentá-las adequadamente. reações orgânicas e/ou comportamentais relacionadas com mudanças psicofisiológicas do organismo, tais como frustrações, sobrecarga de trabalho, questões ambientais (poluição, ruídos, temperatura) e dificuldade de se manter interrelações pessoais e sociais adequadas.

Athayde (2005) fala sobre a primeira corrente ao se referir à obra de Dejours Da Psicopatologia à Psicodinâmica do Trabalho, a qual não trata do trabalho apenas em seus aspectos negativos - a psicopatologia do desemprego e da modernização capitalista -, mas propõe-se também como instrumento para perceber as possibilidades do trabalho como estruturante psíquico, os possíveis encaminhamentos do sofrimento em direção ao prazer e à saúde.

Dejours (1987) refere-se a uma relação existente entre a "tensão nervosa"/"nervosismo" com o quadro da neurose e a produtividade. Utiliza como exemplo dessa relação o trabalho das telefonistas, por tratar-se de uma função com as seguintes características: todas as falas são padronizadas, é proibido desligar sob qualquer situação e responder agressivamente ao cliente, as ligações são monitoradas e o desempenho em cada ligação é constantemente avaliado por meio de uma nota dada pelo cliente; em suma, a organização de trabalho das telefonistas favorece o nervosismo. Esse sentimento gera agressividade que não pode voltar-se para o cliente, mas para o próprio indivíduo, como culpa em um processo no qual a frustração alimenta a disciplina e o comportamento de trabalho condicionado. Nesse sentido, aumenta o ritmo de trabalho/produtividade em uma relação que Dejours denomina compensação.

Tais situações de trabalho, portanto, tão características desse tipo de atividade profissional, têm se estendido para tantas outras categorias, e são decorrentes sobretudo do desenvolvimento tecnológico que se alastra tanto pelas fábricas quanto pelos escritórios, sendo suas consequências negligenciadas ou minimizadas há muito tempo.

O autor aborda também a possibilidade de descompensação psiconeurótica, que se traduz, provavelmente, por uma queda do desempenho produtivo. Não existe neurose de trabalho, as descompensações neuróticas dependem, em última instância, da estrutura da personalidade. Entretanto, isso não é suficiente para explicar o momento escolhido pela descompensação, devendo-se levar em conta na relação homem-organização do trabalho: a fadiga (que faz com que o aparelho mental perca sua versatilidade), o sistema frustração-agressividade reativa (que deixa sem saída uma parte importante da energia pulsional) e a organização do trabalho, que se opõe aos investimentos das pulsões e às sublimações.

De acordo com Tamayo, Lima e Silva (2004), o stress ocupacional é resultante das exigências do trabalho e das habilidades do trabalhador para enfrentá-las adequadamente. Determinantes do stress estão relacionados a fatores psicossociais do trabalho bem como à ênfase atual nas competências e habilidades, na precariedade do trabalho e nas privatizações. Os estressores têm sido explicados a partir de fatores específicos do trabalho e de fatores organizacionais e individuais, sendo mais enfatizados os determinantes laborais e organizacionais. Os autores realizaram também um estudo sobre os componentes do clima organizacional que afetam significativamente o stress no trabalho, destacando aspectos como: a falta de participação na tomada de decisões, o controle excessivo no trabalho, a falta de 
comunicação, o grau do nível de formalidade, a liderança gerencial autoritária e a falta de apoio social.

Nascimento e Bulgacov (1999) destacam Aubert, que elaborou o conceito de neurose profissional, como outro autor na Psicopatologia do trabalho.

\section{O conceito de neurose profissional}

Conforme Aubert (1993), o conceito de neurose profissional foi proposto para explicar certos casos de patologias graves já instaladas, relacionadas de forma direta às condições de trabalho e que o conceito de stress parecia insuficiente para explicar. Para o autor, a neurose profissional é definida como "uma afecção psicogênica persistente, na qual os sintomas são expressão simbólica de um conflito psíquico, cujo desenvolvimento se encontra vinculado a uma situação organizacional ou profissional determinada" (p. 87).

O conceito de neurose profissional se relaciona com o conceito psicanalítico de neurose, definida como uma "afecção psicogênica em que os sintomas são a expressão simbólica de um conflito psíquico que tem raízes na história infantil do sujeito e constitui compromissos entre o desejo e a defesa" (Laplanche \& Pontalis, 1983, p. 296).

Para a psicanálise, o que caracteriza a neurose é a situação em que o Ego (instância psíquica de papel intermediário entre outras instâncias e o mundo externo) está ameaçado e prejudicado, e passa a lutar contra os sintomas, gerando uma tensão conflitiva no funcionamento psíquico. A frustração (não realização) é determinante na etiologia da neurose, que é resultado de uma representação fracassada, e perturba de algum modo a relação do paciente com a realidade, servindo-lhe como meio de afastarse dela (Freud, 1996).

Aubert (1993) afirma que o conceito de neurose profissional está ligado aos conceitos de stress e burnout. O autor cita estudos precursores que deram sequência à obra de Hans Selye em 1956, sendo que estudos franceses abordavam a mesma patologia com nomes diferentes. Enquanto os pesquisadores franceses utilizavam o termo "neurose", os outros falavam de "stress". Esse autor ressalta ainda que a diferença entre stress profissional e neurose profissional estaria no fato de esta se tratar de um estado de desorganização persistente da personalidade. Nesse sentido, se as fontes de stress persistem de maneira intensa e repetida, podem ter como consequência a neurose profissional.

De acordo com Aubert (1993), a neurose profissional apresenta três formas clínicas: 1) neurose profissional atual ou neurose traumática, sendo esse conceito diferente daqueles dados por Freud; a neurose traumática é a única que depende de um acontecimento de fora (determinismo exterior) para perturbar a personalidade do indivíduo, e envolve um conflito cuja origem está na própria situação profissional em si, sem remeter particularmente a um conflito infantil. A autora enfatiza ainda que a origem desses conflitos não deve se restringir à infância, já que todos os acontecimentos e experiências posteriores da existência podem também estar na origem de processos neuróticos; 2) psiconeurose profissional, na qual uma situação de trabalho funciona como desencadeante de um conflito infantil que permanecia no inconsciente, e 3) neurose de excelência: nesse caso, certas situações organizacionais podem provocar, em alguns 
tipos de personalidade que buscam um ideal profissional elevado e dirigem intensamente seus esforços e ideais para determinadas atividades da organização, o estabelecimento de processos neuróticos.

De acordo com Seligmann-Silva (2003), a ideologia da excelência foi inicialmente identificada na origem do quadro clínico denominado por Aubert e Gaulejac como neurose de excelência. Essa ideologia pode ser reconhecida como uma cultura da excelência, na qual há valores instaurados que influenciam os comportamentos das pessoas e que passaram a compor crenças e mitos. Ela atinge também a própria cultura do entorno social mais amplo, que inclui os indivíduos que estão fora do trabalho, como aqueles que ainda vão ingressar no mercado. Os elementos constituintes dessa ideologia da excelência correspondem à competitividade, à flexibilidade, ao culto à velocidade e à agilidade, à evitação dos sentimentos, ao apagamento da ética e à polivalência. Esses componentes ampliam as possibilidades quanto ao desenvolvimento ou não de um sofrimento mental que pode se tornar patológico.

Magnólia (2004), ao abordar o tema neurose organizacional, comenta que as organizações adotam estratégias para manter o vínculo com as pessoas cada vez mais afetivo, criando nos trabalhadores a fantasia de que a organização é a mantenedora e a protetora. A neurose organizacional, de acordo com a autora, surge em decorrência de situações como falta de coerência entre o discurso adotado pela empresa e a prática e demandas de trabalho impossíveis de serem alcançadas, entre outras.

A autora aborda também o fato de que existem outras situações aliadas ao tipo de gestão organizacional que aumentam as possibilidades de idealização, de maneira a produzir mais carências e estreitar a dependência à organização. Entre elas está a necessidade de se manter o emprego em função do desemprego estrutural, a instabilidade econômica, as perdas salariais e o abandono do Estado em relação à saúde, à educação e à moradia, fazendo com que haja aceitação de que as empresas assumam esse papel familiar, infantilizando, assim, as relações de trabalho.

Mendes e Cruz (2004), embora não usem o termo neurose profissional, afirmam que o trabalho pode funcionar como colaborador ou desencadeador das doenças ditas mentais. No primeiro caso, tais desordens desaparecem quando a situação provocadora é transformada; já no segundo, o indivíduo tem uma estrutura psíquica com certas características (falta de maturidade afetivoemocional, dificuldades de relacionamento, intensidade e qualidade dos vínculos afetivos, etc.), que o predispõem a determinados tipos de adoecimento. Essa angústia vivenciada não é facilmente sanável com a transformação do contexto de trabalho, pois encontra-se relacionada a conflitos intrapsíquicos e a outras esferas de vida das pessoas.

De acordo com o Ministério da Saúde (2001), a neurose profissional se caracteriza por quadros de evolução crônica, que tendem a se definir como um padrão de comportamento. Alguns fatores de risco de natureza ocupacional conhecidos são descritos na CID-10 (sessão Z55-Z65), e estão vinculados a circunstâncias socioeconômicas e psicossociais, tais como: problemas relacionados ao emprego e ao desemprego (Z56.), desemprego (Z56.0), mudança de emprego (Z56.1), ameaça de perda de emprego (Z56.2), ritmo de trabalho penoso (Z56.3), má adaptação ao trabalho - 
condições difíceis de trabalho (Z56.5) e outras dificuldades físicas e mentais relacionadas ao trabalho (Z56.6).

O Ministério da Saúde ressalta ainda a dificuldade de classificação da neurose profissional, pois ela não se enquadra nas classificações psiquiátricas estabelecidas internacionalmente. Os sintomas apresentados são inespecíficos: cansaço, desinteresse, irritabilidade, alterações do sono (insônia ou sonolência excessiva), inibição para o trabalho (a pessoa que antes trabalhava disposta não consegue mais trabalhar nem explicar os motivos exatos).

Considerando que a persistência de fontes de stress no trabalho pode ter como consequência a neurose profissional, torna-se importante uma reflexão acerca do diagnóstico e das possibilidades de intervenção de diferentes naturezas preventivas e remediadoras.

\section{O diagnóstico da neurose profissional e as possibilidades de intervenção do psicólogo organizacional}

O diagnóstico da neurose profissional é formado a partir das queixas mencionadas, da história de trabalho do indivíduo e da análise de sua situação de trabalho atual. $\mathrm{Na}$ neurose de excelência, por exemplo, os valores pessoais caracterizados pelo alto nível de exigência são determinantes que se articulam com a cultura organizacional em que a excelência é imperativa (Ministério da Saúde, 2001).

Quando os sintomas comprometem a vida do trabalhador, o Ministério da Saúde cita como forma de tratamento, além da psicoterapia individual, uma ação integrada que aborde o atendimento por parte de uma equipe multiprofissional, capacitada para lidar e dar suporte ao sofrimento psíquico do trabalhador e aos aspectos sociais e de intervenção nos ambientes de trabalho.

Como prevenção, o órgão salienta ainda a importância de mudanças na cultura da organização do trabalho, como o estabelecimento de restrições à exploração do desempenho individual por meio de metas coletivas que considerem o bem-estar de cada trabalhador.

Após estabelecer o nexo causal entre a doença e o trabalho, o profissional e a equipe de saúde responsável devem assegurar: a orientação ao trabalhador e a seus familiares quanto ao seu problema de saúde e os encaminhamentos necessários, o afastamento do trabalho, caso a permanência do trabalhador represente um fator de agravamento do quadro, o estabelecimento da terapêutica adequada, solicitação da emissão de Comunicação de Acidente no Trabalho (CAT) à empresa, notificação da ocorrência aos órgãos competentes autoridade sanitária, Delegacia Regional do Trabalho (DRT/TEM) e o sindicato da categoria a que o trabalhador pertence (Brasil, 2001). Destaca-se ainda a participação do psicólogo organizacional entre os profissionais dessa equipe multiprofissional que deve atender a pessoa portadora de neurose profissional. O estudo de Garbin (2006) contribuiu com o debate acerca da prática profissional na área da saúde do trabalhador, destacando a atuação do psicólogo e as perspectivas de trabalho nesse segmento.

Dessa forma, o psicólogo, para compreender o adoecer e o sofrer dos trabalhadores, deve considerar a subjetividade do indivíduo, ou seja, o conjunto de valores, crenças e o significado que os indivíduos atribuem a determinadas situações em um contexto 
social, promovendo mudanças nas condições e processos de trabalho, com enfoque no coletivo dos trabalhadores (Maemo \& Carmo 2005, citado por Garbin, 2006). A análise do sofrimento psíquico resulta da confrontação do homem frente à organização do trabalho, portanto, há que se analisar a fadiga mental, a falta de controle sobre o tempo, o trabalho monótono, o distanciamento entre o planejamento e a execução, o acúmulo de tarefas e a hierarquia rígida entre outras condições de trabalho que interferem na condição de saúde do trabalhador (Spink, 1982, citado por Garbin, 2006).

O psicólogo, ao apropriar-se do pensamento sistêmico, deve estar atento ao decorrer do diagnóstico e às possibilidades de intervenção não só com relação à neurose profissional mas também aos demais transtornos mentais, em uma visão que abranja o indivíduo como um todo; em outras palavras, deve lançar um olhar atento sobre o indivíduo, o grupo, a organização e o contexto social desse indivíduo.

É importante considerar que existem campos inexplorados para a atuação do psicólogo nas organizações de trabalho, principalmente no que se refere às práticas promotoras de saúde mental do trabalhador. Segundo Fiorelli (2001), esses campos inexplorados compreendem, principalmente,

\section{a) a obtenção e a divulgação de informações} sobre saúde mental, em que um diagnóstico eficaz se torna ferramenta imprescindível para atuar sobre a questão. Ao psicólogo organizacional cabe, por meio de mecanismos existentes na organização ou com a criação de outros específicos, buscar estabelecer processos contínuos e adequados de informações relacionadas à saúde mental e a transtornos mentais que são merecedores da atenção da comunidade. Outra questão importante é implementar estudos e pesquisas a respeito do assunto, como, por exemplo, a influência dos transtornos mentais sobre a produtividade;

\section{b) a identificação das situações de conflito,}

ou seja, identificar os estímulos ansiogênicos relacionados com as tarefas e os processos da organização. O psicólogo, mediante esses estudos e a identificação das situações conflituosas, poderá fornecer informações objetivas aos gestores organizacionais com a finalidade de neutralizar e/ou reduzir o nível de ansiedade gerada por essas situações. Cabe também ao profissional de Psicologia identificar as incongruências entre as responsabilidades e a autoridade atribuída a cada cargo e pessoa dentro da organização, apontando também as incompatibilidades entre os requisitos comportamentais do cargo e as características dos indivíduos; deve também estar atento às incongruências nas exigências dos superiores aos subordinados, que envolvem metas incompatíveis com possibilidades de desempenho, alterações frequentes de requisitos sem o devido tempo hábil para adaptações, exigências de competências não amparadas por treinamentos adequados, etc.;

\section{c) a neutralização das situações ansiogênicas,} desenvolvendo ou participando de processos para identificação e orientação de profissionais no que tange a relacionamentos interpessoais no trabalho, em atuação conjunta com outros profissionais da área da saúde. Deve desenvolver treinamentos especializados em habilidades interpessoais assim como procedimentos para lidar com situações pós-traumáticas que envolvam os trabalhadores e seus familiares, oferecendo suporte emocional e apoiando profissionais em processo de readaptação ao trabalho, e 
atuar para desenvolver novos procedimentos de trabalho, visando a neutralizar as situações de conflitos identificadas;

\section{d) a participação e o planejamento programas de promoção da saúde no} trabalho, buscando desenvolver nos profissionais uma atitude favorável à promoção da saúde mental no trabalho, com o acompanhamento das atividades realizadas por especialistas médicos, a participação em procedimentos específicos envolvendo avaliação psicológica, o desenvolvimento de estratégias de aproximação adequadas e a consideração dos aspectos culturais e sociais da organização, entre outras.

Conforme aponta o Ministério da Saúde (Brasil, 2001), é imprescindível considerar o relato do indivíduo e o do grupo do qual faz parte, suas impressões e sentimentos em relação ao trabalho, de forma individual ou coletiva, pois, muitas vezes, apenas o trabalhador sabe descrever as reais condições, circunstâncias e imprevistos que ocorrem no cotidiano e que são capazes de explicar o adoecimento. No âmbito individual, o principal instrumento para o diagnóstico correto é representado pela anamnese ocupacional.

Esta última faz parte da entrevista médica, que corresponde à história clínica atual, à investigação sobre diversos sistemas ou aparelhos, aos antecedentes pessoais e familiares, à história ocupacional, aos hábitos e estilo de vida, ao exame físico e à propedêutica complementar. Devem-se levar em conta também fatores como as ocupações anteriores do trabalhador, dada a variabilidade dos períodos de latência requeridos para o surgimento de uma patologia, uma leitura técnica especializada, a observação direta do posto de trabalho, a análise ergonômica da atividade, a descrição de produtos químicos, quando utilizados, e a ficha toxicológica. No âmbito coletivo, destacam-se os estudos descritivos de morbidade e mortalidade e os estudos analíticos, tipo caso-controle.

Ao se pensar em possibilidades de intervenção, é inevitável abordar a questão dos valores em nossa sociedade atual. Segundo Tamayo et al. (2004), os valores constituem o núcleo da cultura organizacional, e indicam a possibilidade de utilizar a cultura em pesquisas empíricas para verificar seu impacto sobre o comportamento organizacional, por meio da análise de fatores como a influência dos valores, das práticas laborais, do padrão ou estilo de gestão e do clima organizacional.

Para Vasconcellos (2007), quando se fala de valores, fala-se de formas de "inter-agir", de "con-viver", formas de relação fundadas na emoção amor - amor, entendidas como as nossas ações/interações, como formas de nos relacionarmos. Nesse sentido, ressalta-se que valores não se ensinam, nem se aprendem por meio da literatura ou de instruções, mas vivem-se e aprendem-se na convivência.

A autora chama a atenção para as contradições de valores disseminadas pelas famílias contemporâneas. Ao mesmo tempo em que se busca desenvolver aptidões específicas para a capacidade competitiva e a superação de limitações, fala-se da família como um lugar no qual são testados e aprimorados modelos de convivência que visam à criação de uma sociedade mais harmônica e promotora do bem-estar coletivo. Essas contradições podem ser observadas no âmbito de todas as nossas relações, seja na família, seja no trabalho.

Pode se dizer que essas contradições de valores, a incoerência entre as palavras e as 
práticas com relação aos valores, têm causado incertezas, medos e, em consequência, adoecimento ao ser humano.

Apesar de todas essas dificuldades e desafios, algumas formas de prevenção da neurose profissional podem ser citadas, como, por exemplo, o enriquecimento no conteúdo das tarefas em trabalhos monótonos e repetitivos e o incremento da participação dos trabalhadores nos processos de decisão, garantindo-lhes a autonomia para organizar o trabalho e diminuindo as pressões de tempo e de produtividade, entre outras intervenções sobre as condições de trabalho (Brasil, 2001).

Outra ação de prevenção está no âmbito da proteção individual, por meio da educação e da informação do trabalhador, o que implica mudanças de comportamento dos trabalhadores e das chefias. Destacam-se também a melhoria geral das condições coletivas de trabalho - uma gestão participativa - e ações de vigilância em saúde ou de controle médico, por meio de uma avaliação médica e psicológica, feita periodicamente, para a prevenção de doenças relacionadas ao trabalho.

\section{Considerações finais}

As transformações sociais que têm afetado a todos nós, em decorrência de sucessivas crises econômicas, políticas e financeiras, da introdução de novas tecnologias no mundo do trabalho e da consequente exclusão social dos segmentos menos qualificados, da precarização das condições de trabalho, do aumento da pressão por qualidade e produtividade, da perversidade nas formas de organização e no gerenciamento do trabalho, da submissão a ritmos, ordens e a cargas de trabalho desumanas, do medo de perder o emprego e da ausência de significado em relação ao que fazem, dentre tantos outros fatores, têm trazido danos à saúde física e mental dos trabalhadores, de maneira mais acentuada para os segmentos de menor poder aquisitivo.

Dessa maneira, o trabalho se apresenta como fonte de sofrimento, exploração e adoecimento, em vez de garantir prazer, reconhecimento e significado à vida do trabalhador. Assim, os transtornos mentais, como a neurose profissional, resultam de uma complexa combinação de fatores biológicos, psicológicos e sociais.

Observou-se, portanto, que a neurose profissional consiste em um conceito psicanalítico relacionado a outros conceitos como o stress e burnout. O psicólogo deve estar atento à semelhança entre esses conceitos para poder compreender, identificar, prevenir e se comunicar com outros profissionais.

Apesar de ainda existir uma carência na literatura sobre o tema estudado, em especial a relacionada ao mundo do trabalho, é importante ampliar a discussão sobre os fatores de risco no trabalho assim como os determinantes psíquicos para o desenvolvimento da neurose profissional.

Em relação à atuação do psicólogo organizacional nas organizações, é importante que esses profissionais reconheçam e estejam preparados para atuarem além das práticas tradicionais já consolidadas, como o recrutamento e seleção e o treinamento e desenvolvimento, por exemplo. Novas demandas estão se apresentando, decorrentes das relações do trabalho contemporâneo, para as quais a contribuição da Psicologia pode ser de extrema relevância. É importante também considerar o fato de que as instituições de ensino, formadoras dos novos profissionais psicólogos, 
possam atuar para preparar esses profissionais no sentido de atender a essas novas demandas que se revelam nas mais diferentes esferas sociais, por meio de projetos pedagógicos que favoreçam o desenvolvimento de competências compatíveis com essas novas exigências. Enfim, a atuação do psicólogo nas organizações de trabalho, especificamente, possui muitas frentes ainda inexploradas que precisam receber a devida atenção desses profissionais e para as quais precisam estar preparados, primeiramente para reconhecê- las, ou seja, diagnosticá-las, e depois para intervir adequadamente.

É importante, ainda, que, além do psicólogo, outros profissionais que atuam nas organizações, especialmente na área de gestão de pessoas, exerçam influência nos segmentos de maior poder hierárquico e coparticipem do processo de elaboração de políticas de prevenção aos transtornos mentais, com alocação de recursos humanos, financeiros e técnicos destinados a essa finalidade.

\section{Ludmilla Cristine Santos}

Licenciada em Psicologia pela Universidade Estadual Paulista Júlio de Mesquita Filho (UNESP), campus de Bauru, Bauru, SP - Brasil.

E-mail: cristineludpsico@yahoo.com.br

\section{Pérola Lozano Teixeira de Carvalho}

Licenciada em Psicologia pela Universidade Estadual Paulista Júlio de Mesquita Filho (UNESP), campus de Bauru, Bauru, SP - Brasil.

E-mail: perolalozano@yahoo.com.br

\section{Edward Goulart Júnior}

Doutor em Psicologia e professor do Departamento de Psicologia da Universidade Estadual Paulista Júlio de Mesquita Filho (UNESP), campus de Bauru, Bauru, SP - Brasil.

E-mail: edward@fc.unesp.br

\section{Luiz Carlos Canêo}

Doutor em Educação e professor do Departamento de Psicologia da Universidade Estadual Paulista Júlio de Mesquita Filho (UNESP), campus de Bauru, Bauru, SP - Brasil.

E-mail: lcc@travelnet.com.br

\section{Maria Cristina Frollini Lunardelli}

Doutora em Educação e professora do Departamento de Psicologia da Universidade Estadual Paulista Júlio de Mesquita Filho (UNESP), campus de Bauru, Bauru, SP - Brasil.

E-mail: mlunardelli@uol.com.br

Endereço para envio de correspondência:

Universidade Estadual Paulista Júlio de Mesquita Filho, Faculdade de Ciências de Bauru, Departamento de Psicologia Avenida Luiz Edmundo Carrijo Coube, s/n,Vargem Limpa - Bauru, SP - Brasil - CEP 17033-360, Caixa-Postal: 473. 


\section{Referências}

Albuquerque, J. A. G. (1978). Metáforas da desordem. Rio de Janeiro: Paz e Terra.

Athayde, M. (2005, maio/junho). Christophe Dejours: da psicopatologia à psicodinâmica do trabalho. Cadernos de Saúde Pública, 21(3), 988-990.

Aubert, N. A. (1993, janeiro/fevereiro). Neurose profissional. Revista Administração de Empresas, 33(1), 84-105. Recuperado em 20 de abril de 2008, do portal RAE: www.rae.br/rae/index. cfm?FuseAction

Brasil. Ministério da Saúde. (1999). Portaria no 1.339 de 18 de novembro de 1999. Dispõe sobre a lista de doenças relacionadas ao trabalho. Diário Oficial da União, (Seção I), p. 21.

Brasil. Ministério da Saúde. (2001). Doenças relacionadas ao trabalho: manual de procedimentos para os serviços de saúde. Brasília, DF: Autor

Camargo, D. A., \& Neves, S. N. H. (2004). Transtornos mentais, saúde mental e trabalho. In L. A. M. Guimarães \& S. Grubits (Eds.), Saúde mental e trabalho (Vol. 3, pp. 23-40). São Paulo: Casa do Psicólogo.

Codo, W., Soratto, L., \& Vasquez-Menezes, I. (2004). Saúde mental e trabalho. In J. C. Zanelli, J. E. Borges-Andrade \& A. V. B. Bastos (Eds.), Psicologia, organizações e trabalho no Brasil (pp. 276-299). Porto Alegre: Artmed.

Cooper, C., \& Kelly, M. (1993). Ocupational stress in head teachers: A nacional UK study. British Journal of Educational Psychology, 63, 130-143;

Correia, A. C. (2000). Um instante de reflexão sobre o homem e o trabalho. Caderno de Pesquisas em Administração, 1(11), 12-17.

Dejours, C. (1987). A loucura do trabalho: estudo de psicopatologia do trabalho. São Paulo: Oboré.

Fiorelli, J. O. (2001). Psicologia para administradores: integrando teoria e prática (2a ed.). São Paulo: Atlas.

Freud, S. (1996). Neurose e psicose. In S. Freud, Coleção brasileira das obras psicológicas completas de Sigmund Freud. Rio de Janeiro: Imago.

Garbin, A. C. (2006). A Psicologia na área da saúde do trabalhador. In E. Goulart Júnior, M. C. F. Lunardelli \& L. C. Canêo (Eds.), Contribuições do psicólogo para a promoção da saúde, qualidade de vida do trabalhador e desenvolvimento das organizações (pp. 113-118). Bauru, SP: Joarte.
Glina, D. M. R., Rocha, L. E., Batista, M. A., \& Mendonça, M. G. V. (2001, maio/junho). Saúde mental e trabalho: uma reflexão sobre o nexo com o trabalho e o diagnóstico, com base na prática. Cadernos de Saúde Pública, 17(3), 607-616.

Guimarães, L. A. M., Cardoso, W. L. C. D., Grubits, S., \& Martins, D. A. (1999). Prevalência de transtornos mentais no ambiente de trabalho. In L. A. M. Guimarães \& S. Grubits (Eds.), Saúde mental e trabalho (Vol. 1, pp. 49-57). São Paulo: Casa do Psicólogo.

Laplanche, J., \& Pontalis. J. B. (1983). Vocábulo de psicanálise. São Paulo: Martins Fontes.

Magnólia, A. (2004, abril). As organizações não são "jardins de infância"! A neurose organizacional e a saúde dos trabalhadores. Recuperado em 15 de março de 2008, do Conselho Regional de Psicologia da $16^{\text {a }}$ Região: http://www.psicologia.online. org.br

Mendes, A. M., \& Cruz, R. M. (2004). Trabalho e saúde no contexto organizacional: vicissitudes teóricas. In A. Tamayo (Ed.), Cultura e saúde nas organizações (pp. 39-55). Porto Alegre: Artmed.

Nascimento, M. R., \& Bulgacov, S. (1999, setembro). Mudança organizacional e estresse ocupacional. In Resumos dos Trabalhos EnANPAD 99, 23 Encontro da Associação Nacional de Pós-Graduação e Pesquisa em Administração. Foz do Iguaçu, PR: Associação Nacional de Pós-Graduação e Pesquisa em Administração. Recuperado em 10 de março de 2008, de: http://www.anpad.org.br.

Resende, H. (1987). Política de saúde mental no Brasil: uma visão histórica. In N. R. Costa \& S. A. Tundis (Eds.), Cidadania e loucura - políticas de saúde mental no Brasil (pp. 15-73). Petrópolis, RJ: Vozes.

Selligmann-Silva, E. (2003). Psicopatologia no trabalho: aspectos contemporâneos. In R. Mendes (Org.), Patologia do trabalho (pp. 64-98). Rio de Janeiro: Atheneu.

Tamayo, A., Lima, D., \& Silva, A. V. (2004). Clima organizacional e estresse no trabalho. In A. Tamayo (Ed.), Cultura e saúde nas organizações (pp. 77-101). Porto Alegre: Artmed.

Vasconcellos, M. J. E. (2007). Valores: questões para reflexão do profissional novo-paradigmático. In J. G. Aun, M. J. E. de Vasconcelos \& S. V. Coelho, Atendimento sistêmico de famílias e redes sociais (Vol. 2, Tomo 1, pp. 84-88). Belo Horizonte: Ophicina de Arte \& Prosa. 